\title{
LUT
}

University

\section{Performance measurement system implementation in a turbulent operating environment}

\author{
Pekkola Sanna, Saunila Minna, Rantanen Hannu
}

This is a Post-print

version of a publication

published by Emerald Group Publishing

in International Journal of Productivity and Performance Management

DOI: $10.1108 /$ IJPPM-01-2015-0018

Copyright of the original publication: (C) 2016, Emerald Group Publishing

Please cite the publication as follows:

Pekkola, S., Saunila, M., Rantanen, H. (2016). Performance measurement system implementation in a turbulent operating environment. International Journal of Productivity and Performance Management, vol. 65, issue 7. pp. 947-958. DOI: 10.1108/IJPPM-01-2015-0018

This is a parallel published version of an original publication. This version can differ from the original published article. 
Pekkola, S., Saunila, M. \& Rantanen, H. (2016). Performance measurement system implementation in a turbulent operating environment. International Journal of Productivity and Performance Management, 65(7), 947-958.

\title{
PERFORMANCE MEASUREMENT SYSTEM IMPLEMENTATION IN A TURBULENT OPERATING ENVIRONMENT
}

\begin{abstract}
Purpose - This study aims to examine how a performance measurement system (PMS) can be designed for small- and medium-sized enterprises (SMEs) operating in a turbulent environment. The current models and frameworks for the design and implementation of a PMS are for large companies; these traditional design and implementation processes are too multi-stage and long term for SMEs operating in a rapidly changing environment.
\end{abstract}

Design/methodology/approach - The study constructs a conceptual framework based on the performance measurement and management literature and empirical evidence from a longitudinal case study. Empirical data has been gathered by conducting interviews, analysing strategic documents of case organisation and documenting the performance measurement system design and implementation process.

Findings - The study results reveal the framework for a flexible PMS design. In the framework, the PMS consists of core permanent measures that control the profitability of the company and supportive measures of the realisation of strategic targets. The supportive measures change and develop along with the strategy. The paper also provides empirical evidence about the design and implementation of performance measurement for SMEs.

Originality/value - The study provides new understanding about the performance measurement design process in SMEs operating in a turbulent environment. The existing literature presents performance measurement design and implementation process models for large organisations, but these frameworks are too multi-stage and long term for SMEs.

Keywords - Performance measurement system, SME, turbulent environment 
Pekkola, S., Saunila, M. \& Rantanen, H. (2016). Performance measurement system implementation in a turbulent operating environment. International Journal of Productivity and Performance Management, 65(7), 947-958.

\section{INTRODUCTION}

Small- and medium-sized enterprises (SMEs) are required to compete in globalised and turbulent markets. To survive in such a dynamic environment, companies need to be able to adapt to market changes, satisfy all their stakeholders and excel in all performance dimensions (Neely et al., 2002; Garengo et al., 2005; Cocca and Alberti, 2010; Nudurupati et al., 2011; Barrows and Neely, 2011). The increased volatility of the business environment makes systematic strategic planning and the development process of a performance measurement system (PMS) more difficult than before. Bahri et al. (2011), Garengo et al. (2005) and Hudson et al. (2001) have argued that the PMS of an SME should be extremely flexible and reactive to market changes. In addition, the PMS should take into account the strategic and environmental factors related to the business and consider the organisation's structure, processes, functions and their relationships (Bititci et al., 1997).

The literature presents limited examples of empirical research on performance measurement practices in the SME context based on in-depth case studies (Sousa et al., 2006; Cocca and Alberti, 2010). The literature contains many models and frameworks for the implementation of a PMS in large companies (see, e.g., Kaplan and Norton, 1996; Simons, 2000; De Toni and Tonchia, 2001; Gooderham, 2001). However, the traditional performance measurement implementation processes are too multi-stage and long term for SMEs that operate in a rapidly changing environment. For instance, Kaplan and Norton's (1996) design process consists of 11 stages. These kinds of multistaged design and implementation processes take lots of time and personnel resources that are often limited in SMEs (cf. Brem et al., 2008). Empirical evidence provided by this study reveals that the strategic changes occur so quickly for SMEs that the selected performance measures are already out of date before they are fully implemented. Bititci et al. (2012) emphasise the importance of examining how PMSs evolve in response to changes in the operating environment and how these characteristics are taken into account in SMEs. To provide SMEs with useful and tailored recommendations on improving their performance management process to respond to the challenges of a turbulent environment, it is also necessary to investigate thoroughly the state of their current performance measurement practices.

The aim of this study is to examine how a PMS can be designed for SMEs that operate in a turbulent environment. Empirical data were gathered from one small-sized clothing company in Finland by analysing the performance measurement design and implementation process of its PMS from 2004 to 2014. The empirical data was gathered by conducting interviews, analysing strategic documents and documenting the performance measurement system design and implementation process. Based on the results of the analysis, the study presents a framework for a flexible PMS for SMEs operating in a turbulent business environment. The paper is divided into five sections. The next section is a review of the literature on performance management and measurement 
Pekkola, S., Saunila, M. \& Rantanen, H. (2016). Performance measurement system implementation in a turbulent operating environment. International Journal of Productivity and Performance Management, 65(7), 947-958.

systems in SMEs and in turbulent operating environments. The subsequent sections explain the methodology and findings of the study. The final section offers conclusions and recommendations for practice and further research.

\section{LITERATURE}

\subsection{Turbulent environment and SMEs}

Turbulence refers to volatility or difficulty in predicting discontinuities in an environment (Barrows and Neely, 2011). Rapidly changing conditions outside an organisation and across multiple variables require management teams to interpret those changes more quickly and accurately and respond more decisively than in stable conditions. In turbulent environments, time is lacking; organisations that survive and thrive are those that have mastered the ability to make rapid and effective decisions in the absence of complete information (Barrows and Neely, 2011). SMEs, especially, operate in a highly dynamic and turbulent environment (Hudson et al., 2001; Kennerly and Neely, 2003; Cocca and Alberti, 2010; Nudurupati et al., 2011; Barrows and Neely, 2011). Hence, SMEs have to be innovative and constantly review their processes and practices in order to survive in the market (Bahri et al., 2011). The European Commission defines SMEs as companies that have fewer than 250 employees, an annual turnover not exceeding 50 million euros and/or an annual balance sheet total not exceeding 43 million euros (The Federation of Finnish Enterprises, 2013). Nearly all (99.8\%) companies in Finland are SMEs (The Federation of Finnish Enterprises, 2013). Thus, the research is highly relevant from perspective of academics as well as practitioners.

When turbulence affects the performance of an organisation, the cause or source is often unclear to the organisation's managers. Traditional performance management practices, such as the balanced scorecard, do not work well in turbulent environments (Sousa et al., 2006 Barrows and Neely, 2011; Rompho, 2011; Nudurupati et al., 2011). McAdam (2000) states that the implementation process of the balanced scorecard with four measurement perspectives faces difficulties because it is a resource-intensive system in an environment with typically scarce resources. In addition, in turbulent environments, the need for timely information grows significantly. Managers must detect and interpret information much more rapidly. They must make decisions more quickly with a narrower margin for error (Barrows and Neely, 2011).

Managing performance within the context of SMEs requires an understanding of SME characteristics that influence the design and implementation of performance measurement (Garengo et al., 2005; Ates et al., 2013). Although the size of SMEs results in some weaknesses, it also results in flexibility, adaptability and speed in responding to the changing environment (Garengo et al., 2005). Thus, SMEs usually have a high potential for renewal and the ability to 
Pekkola, S., Saunila, M. \& Rantanen, H. (2016). Performance measurement system implementation in a turbulent operating environment. International Journal of Productivity and Performance Management, 65(7), 947-958.

satisfy customers' emerging and evolving requirements. Furthermore, a structure with few management layers favours face-to-face relations, which simplifies communication processes and offers managers an opportunity to directly influence employees (Singh et al., 2008).

\subsection{Performance measurement in SMEs}

Performance measurement and management in SMEs is still a narrowly studied research area (see, e.g., Garengo et al., 2005; Bititci et al., 2012). The literature presents many models and frameworks for designing and implementing a PMS in a large company (see, e.g., Kaplan and Norton, 1996; Simons, 2000; De Toni and Tonchia, 2001; Gooderham, 2001), but these models do not seem to apply very well to SMEs that operate in a turbulent environment (Cassell et al., 2001; Sousa, 2010; Cocca and Alberti, 2010; Barrows and Neely, 2011; Rompho, 2011). According to Taylor and Taylor (2014), the organisational setting differs between large companies and SMEs. This setting is necessary for supporting and cultivating the PMS implementation process. The current models and frameworks contain processes that are too multi-stage, long term and time consuming for these turbulent environments (Hudson et al., 2001; Garengo, 2005; Cocca and Alberti, 2010). For instance, balanced scorecard design and implementation has nine phases. Previous studies have listed several different challenges relating to performance measurement design and implementation phases in SMEs. Garengo et al. (2005) identify the following challenges:

- It is difficult to involve SMEs in performance measurement projects.

- SMEs do not use any performance measurement model, or they use models incorrectly.

- Many companies often implement only some parts of a general model, while others modify the models without carefully considering the changes made.

- General models are applied correctly but are inadequate for the particular characteristics of SMEs, such as the companies' size.

- Performance measurement implemented in SMEs rarely has a 'holistic approach'.

However, existing literature presents some frameworks for PMSs as well as PMS design and implementation processes for SMEs (e.g., Laitinen, 1996; Chennel 2000; Tenhunen et al., 2011; Garengo et al., 2005, Bahri et al., 2011). For instance, Laitinen (1996) presents integrated performance measurement for small firms (Laitinen 1996). The author defines this model as 'a hybrid accounting system connecting the traditional view and the activity-based costing together in a causal chain'. The model was specifically designed to be used in SMEs. It is based on seven main dimensions of measures, classified as two external dimensions (financial performance and competitiveness) and five internal dimensions (costs, production factors, activities, products and revenues) connected by a causal chain. Tenhunen et al. (2001) studied the PMS design and implementation process in the Finnish SME environment, and as a result they suggest a fivephased design and implementation process. They emphasise the role of clear vision and strategy 
Pekkola, S., Saunila, M. \& Rantanen, H. (2016). Performance measurement system implementation in a turbulent operating environment. International Journal of Productivity and Performance Management, 65(7), 947-958.

because these were less clearly identified in SMEs than in large companies. The study of Chennell et al. (2000) suggests that PMSs should consist of three levels of measures in SMEs. First-level measures are strategic, measuring whether value has been delivered. Second-level measures are tactical, measuring outputs of organisations. Third-level measures are focused on measuring operational processes. Most of the PMS design frameworks are based on several sequential steps and are constructed to assist companies in defining a set of performance objectives and measures. In these frameworks, modification of the measures involves great effort and, in many cases, a rethinking of other involved processes. Thus, they are not suitable for a turbulent environment (cf. Garengo et al., 2005). The study of Bahri et al. (2011) proposes that a PMS should be based on an analysis of the connections between these firms' business practices and performance measured by economic value added (EVA). These studies do not perceive turbulent operating environments as requiring rapid changes of strategy. The study of Brem et al. (2008) concluded that future research should be taken in two directions. First, there is a gap between the formal requirements of PMSs and their existent occurrence, especially in the field of SMEs. Second, problems arise within the scope of the implementation owing to deficient appraisal of the established characteristics of SMEs and lack of structural preparation.

The literature has also identified a number of challenges that SMEs face when they launch a PMS and use it to support performance management (Rantanen, 2001; Hudson et al., 2001; Garengo, 2005; Cocca and Alberti, 2010). These challenges should be considered when developing a PMS design and implementation process for SMEs. The main characteristics that can be obstacles to the implementation of a PMS are as follows (see, e.g., Hudson et al., 2001; Garengo et al., 2005; Singh et al., 2008; Cocca and Alberti, 2010): First, there is a lack of human resources. The number of personnel is inadequate, and the managers do not have time or financial stability for added activities, such as implementing a PMS. Second, skills are limited, not only among the personnel but also among the owners and managers, who often do not have enough managerial expertise or organisational capabilities. This implies poor strategic business planning and human resource management. On the other hand, the lack of bureaucracy has a positive impact on flexibility, adaptability and speed in responding to the changing environment. Third, managerial capacity and culture are also often lacking in these companies. Therefore, managerial tools and techniques are perceived as being of little benefit. Fourth, SMEs take a reactive approach, which means that they are characterised by poor strategic planning and informal decision-making processes. Combined with a lack of resources, SME managers struggle with multiple short-term and long-term priorities at the same time. Strategic management and long-term priorities may be forgotten when day-today operational issues and customer needs take hold (Ates et al., 2013). Fifth, SMEs lack a managerial system and formalised management of the processes. Finally, SMEs face the challenge of misconception of measurement. A PMS can only be effectively implemented when the company 
Pekkola, S., Saunila, M. \& Rantanen, H. (2016). Performance measurement system implementation in a turbulent operating environment. International Journal of Productivity and Performance Management, 65(7), 947-958.

perceives the benefits of the PMS, but SMEs often do not understand the potential advantages of implementing a PMS.

SMEs are less likely than large firms to implement a PMS effectively (Taylor and Taylor, 2014). Given the differences between large firms and SMEs and the lack of knowledge regarding PMS implementation in a turbulent operating environment, more research is needed to investigate what must be done differently for PMS implementation to be effective. To summarise, several different needs, characteristics and challenges should be taken into account when designing and implementing a PMS for SMEs. The turbulent operating environment makes the PMS design and implementation process even more challenging and complicated. Based on these challenges and current measurement practices, PMS design and implementation frameworks and models for SMEs are needed to help design more workable and effective measurement systems (see, e.g., Cocca and Alberti, 2010). For these reasons, the PMS has to be flexible, rapidly changeable and maintainable (Hudson-Smith and Smith, 2007). The results of a study by Hudson et al. (2001) show that the PMS should be very simple, synthetic and information easily collectable; otherwise, the effort needed for measuring would be greater than the benefit gained. In addition, the information collection for the measures should be well defined and resource effective. Hudson $e t$ al. (2001) also emphasise that the performance measurement development process for SMEs must be resource effective and produce notable short-term and long-term benefits. Hudson et al. (2001) and Cocca and Alberti (2010) state that it would be better to use only a few vital measures reported in an effective manner, e.g., graphically and visually. Bititci et al. (2012) stress the need for research to understand how PMSs can be used and how they can adapt to the changing operating environment.

\section{METHODOLOGY}

\subsection{Research design}

The aim of this study is to examine how a PMS can be designed for SMEs that operate in a turbulent environment. SMEs were chosen as the target group of this research due to their remarkable role in the Finnish economy. Finland has over 320,000 enterprises, of which 99.8 per cent are SMEs. As many as 63 per cent of all private-sector employees work for SMEs. These enterprises generate about 50 per cent of the combined turnover of all Finnish businesses. SMEs are responsible for more than 13 per cent of Finland's export revenue (The Federation of Finnish Enterprises, 2013).

This is a longitudinal, single-case study. The case study has consistently been one of the most powerful methods used in management research, particularly when it comes to the development of a new theory (Voss et al., 2002). A case study focuses on creating an understanding of a certain 
Pekkola, S., Saunila, M. \& Rantanen, H. (2016). Performance measurement system implementation in a turbulent operating environment. International Journal of Productivity and Performance Management, 65(7), 947-958.

phenomenon (Eisenhardt, 1989). Voss et al. (2002) cited the following three strengths of case research: 1) the phenomenon can be studied in its natural setting; 2) the method provides answers to the why, what and how questions with a relatively full understanding of the nature and complexity of the complete phenomenon, and 3) the method is useful when the variables are unknown and the phenomenon is not fully understood. A single-case study is an appropriate research design under several circumstances. First, it is analogous to a single experiment because many of the conditions justifying a single experiment are also applicable to a single-case study. One rationale concerns a critical case used for testing a well-formulated theory. The second rationale pertains to a case representing an extreme or unique model. From the perspective of the present case, the existing literature reveals minimal practical experience of PMSs in SMEs. Thus, the case under study is unique because it provides new, practical information regarding the design of PMSs for SMEs. The third rationale involves the use of a revelatory case (Yin, 2009); that is, an investigator has an opportunity to observe and analyse a previously inaccessible phenomenon. Occasionally, for example, in extreme or polarized situations, successful and unsuccessful cases are selected (Eisenhardt, 1989).

Empirical data for the study were collected from 2004 to 2014. The data were gathered by theme interviews, analysing the strategic documents and observing the PMS design process during these years. One researcher participated as an observer in the PMS design and implementation process. The researcher documented all workshops and meetings for research purposes. To increase the validity of the research, in 2013 the interview portion of the study was carried out. In it, results from the documented observations and analysis of the strategic documents were presented and discussed. The interviewees were the executive group of the company, including the chief executive officer (CEO), administrative manager, financial manager and R\&D manager. The interviews focused on the strategic changes and their causes, as well as the choices of performance measures. Results are empirically valid when the theory-building process is tied to empirical observations during the research process (Eisenhardt, 1989).

\subsection{Empirical call for new PMS tools}

The case company is a small-sized Finnish family business established in 1919. It operates in the fashion business, which is sensitive to economic and external changes. In this company, the design work is done in Finland, and the collections are produced in different parts of the world, e.g., Estonia, Turkey and China. Fifty per cent of the company's production is exported at the most, its most important export markets being Russia and the Nordic countries. The other half of the company's production is sold in its own stores in Finland and via its own dealers. The company employs around 20 people. The challenge for this company is strict price compensation as well as the number of companies in the market. In addition, the company's products are known for their quality, and the product prices are higher than the general market level. The market is also very 
Pekkola, S., Saunila, M. \& Rantanen, H. (2016). Performance measurement system implementation in a turbulent operating environment. International Journal of Productivity and Performance Management, 65(7), 947-958.

sensitive to economic changes, e.g., production costs and citizens' purchasing power; hence, the strategic changes are continuous. Table 1 combines the empirical evidence from the case company by identifying key strategic changes and states of the PMS from 2004 to 2014.

Table 1. Strategic changes and measurement development of the case company

\begin{tabular}{|c|c|c|}
\hline Year & Strategic changes & State of PMS \\
\hline 2004 & $\begin{array}{ll}\text { - } & \text { Ending own production and outsourcing to the } \\
\text { Baltic countries } \\
\text { - } \quad \text { R\&D in two parts } \\
\text { - } \quad \text { Exporting clothes to Norway, Russia, Baltic } \\
\text { countries, Ukraine, the UK, Belgium, the } \\
\text { Netherlands, Austria and Switzerland } \\
\text { - } \quad \text { Selling clothes via a reselling network and own } \\
\text { stores } \\
\text { - New values }\end{array}$ & $\begin{array}{l}\text { PMS design and } \\
\text { implementation process } \\
\text { begins }\end{array}$ \\
\hline 2005 & $\begin{array}{ll} & \text { Production moved to China (10\% of total } \\
\text { production, target } 20 \%) \\
\text { - } & \text { New web marketing strategy }\end{array}$ & $\begin{array}{l}\text { Key measures: growth, } \\
\text { return on investment (ROI) } \\
\text { and earnings before interest } \\
\text { and taxes (EBIT) } \\
\text { - } 7 \text { perspectives and } 51 \\
\text { measures }\end{array}$ \\
\hline 2006 & $\begin{array}{l}\text { - } \quad \text { Main target: } 50 \% \text { of production in China } \\
\text { - } \quad \text { Expanding the product development to China } \\
\text { - } \quad \text { Biggest export countries: Russia, Sweden, } \\
\text { Norway, the UK and Ireland }\end{array}$ & $\begin{array}{l}\text { - Key measures: growth, ROI } \\
\text { and EBIT } \\
\text { - New version of PMS: } 7 \\
\text { perspectives and } 28 \\
\text { measures }\end{array}$ \\
\hline 2007 & $\begin{array}{ll}- & 60 \% \text { of production in China } \\
- & \text { New production countries: Turkey, Romania } \\
& \text { and Ukraine } \\
- & \text { No more production in Estonia } \\
- & \text { New store concept } \\
- & \text { Web store development }\end{array}$ & $\begin{array}{l}\text { Challenge: selected } \\
\text { performance measures are } \\
\text { already out of date before } \\
\text { they are fully implemented }\end{array}$ \\
\hline 2008 & $\begin{array}{l}\text { Developing own reselling network in Russia } \\
\text { and Ukraine } \\
\text { - Main target: centralising export to Russia, } \\
\text { Sweden, Norway and the UK } \\
\text { - } 7 \text { own stores in Finland }\end{array}$ & $\begin{array}{ll}- & \text { Key measures: growth, ROI } \\
& \text { and EBIT } \\
\text { - } & \text { Logistics costs emphasised } \\
- & \text { Profit, sales and income of } \\
& \text { own stores } \\
- & \text { Brand }\end{array}$ \\
\hline 2009 & $\begin{array}{ll}\text { - } & 11 \text { own stores } \\
- & 2 \text { own stores in St. Petersburg } \\
- & \text { Moved part of the production from China to } \\
\text { Turkey } \\
\text { - }\end{array}$ & $\begin{array}{ll}\text { - } & \text { Key measures: growth, ROI } \\
& \text { and EBIT } \\
\text { - } & \text { Turnover of the products } \\
\text { - } & \text { Profit, sales and income of } \\
& \text { own stores }\end{array}$ \\
\hline
\end{tabular}


Pekkola, S., Saunila, M. \& Rantanen, H. (2016). Performance measurement system implementation in a turbulent operating environment. International Journal of Productivity and Performance Management, 65(7), 947-958.

\begin{tabular}{|c|c|c|}
\hline 2010 & $\begin{array}{ll}\text { - } & \text { Moved some of the production back to Estonia } \\
\text { - } & \text { More production in Turkey } \\
\text { - } & \text { Reduced export }\end{array}$ & $\begin{array}{ll}\text { - } & \text { Key measures: growth, ROI } \\
& \text { and EBIT } \\
\text { - } & \text { Store-specific measures } \\
& \text { (sales, profit, income) }\end{array}$ \\
\hline 2011 & $\begin{array}{ll} & \text { Most important markets: Finland, Sweden and } \\
\text { Russia } \\
\text { - } \quad \text { New store concept }\end{array}$ & $\begin{array}{ll}\text { - } & \text { Key measures: growth, ROI } \\
& \text { and EBIT } \\
\text { - } & \text { Costs } \\
- & \text { Sales }\end{array}$ \\
\hline 2012 & $\begin{array}{l}\text { - } 60 \% \text { of production in China, } 20 \% \text { in Turkey and } \\
20 \% \text { in Estonia } \\
-\quad \text { Stocks outsourced }\end{array}$ & $\begin{array}{ll}\text { - } & \text { Key measures: growth, ROI } \\
& \text { and EBIT } \\
- & \text { Sales } \\
\end{array}$ \\
\hline 2013 & $\begin{array}{ll} & \text { New web store } \\
- & \text { St. Petersburg's stores closed } \\
- & 6 \text { own stores and } 3 \text { shop-in-shop stores }\end{array}$ & $\begin{array}{ll}- & \text { Key measures: growth, ROI } \\
& \text { and EBIT } \\
- & \text { Sales }\end{array}$ \\
\hline 2014 & $\begin{array}{l}5 \text { own stores, } 3 \text { shop-in-shop stores and } 1 \\
\text { independent reseller store }\end{array}$ & $\begin{array}{ll}\text { - } & \text { Key measures: growth, ROI } \\
& \text { and EBIT } \\
\text { - } & \text { Sales } \\
- & \text { Customer segmentation } \\
& \text { evaluation } \\
\end{array}$ \\
\hline
\end{tabular}

The PMS design and implementation process began in 2004 when the company selected measurement perspectives and measures. The basis of the PMS development in the case company was the balanced scorecard and the balanced view of operations. As shown in Table 1, the first version of the PMS included seven perspectives and 51 measures. The empirical evidence reveals that the implementation process was very challenging. The challenges are related to number of measurement perspectives and measures. The CEO of the case company stated that 'the selected performance measures are already out of date before they are totally implemented'. Other challenges, such as the lack of resources, also affected the PMS implementation. The global recession in 2008 increased the challenges to the fashion industry, e.g., outsourcing of production, and made the PMS implementation process a difficult task for the company because of the wide strategic changes. To cope with increased competition, companies search for cheaper production countries and logistics solutions. In a highly turbulent environment, companies must be able to make quick strategic changes to survive the tightening competition.

This economic situation increases the need for more timely information to manage operations and identify the impacts of strategic changes. Based on these needs, the company started to utilise three key measures and some additional measures that supported the translation of the strategy into action. These three key measures (ROI, EBIT, growth) measure the profitability of the company. Table 1 shows that these three measures have remained the same despite strategic changes. In addition, the results of the study reveal that there are many different measures that support the key measures and easily adapt to the strategic changes and demands. 
Pekkola, S., Saunila, M. \& Rantanen, H. (2016). Performance measurement system implementation in a turbulent operating environment. International Journal of Productivity and Performance Management, 65(7), 947-958.

\section{A FLEXIBLE PERFORMANCE MEASUREMENT SYSTEM FOR SMES}

This study combines the results from the literature that present characteristics of PMSs in SMEs and empirical evidence from a single case and presents the flexible performance measurement system (FPM) framework for SMEs (see Figure 1). The FPM framework accounts for the reality of prevailing environmental uncertainty and complexity and perceives the limited time and personnel resources of SMEs for designing, implementing and using PMS systems in their management.

The FPM contributes to the general characteristics of PMS in SMEs: owner focus, high flexibility, fast fit to market changes, less process formalisation, and a focus on daily business (cf. Garengo et al., 2005; Bahri et al., 2011). To cover these characteristics, the developed framework consists of two levels of measures: core measures and supportive measures. The core measures produce performance information on the profitability of the company. These measures, such as turnover, earnings before interest and taxes and growth, give a general view of the performance of the company. The core measures are permanent and unaffected by strategic changes. These few vital measures help the managers focus on the key performance factors and make quick decisions, as Cocca and Alberti (2010) suggested. These measures are owner focused and give information on the financial state of the business. The measures also enable performance comparison and forecasting over a longer period.

The FPM contributes to the characteristics of flexibility, fast fit to market changes and less process formalisation by suggesting that part of the measures of PMSs are supportive measures. This means that they support the core measures and that they change and develop along with the strategic movement and changes of the operations; for example, new logistics chains or new production countries. These supportive measures can help to evaluate how the current strategy translates into action and how the current development actions and changes affect the company's efficiency and effectiveness in meeting customer's needs. In doing so, they help to determine whether these changes create expected value for the company. The supportive measures make this framework flexible, resource effective and quickly adaptable. The core measures ensure the profitability of the company despite current strategy choices. The supportive measures change according to strategic changes or new innovations. The managers can create new measures and change them timely and easily. These changes are easy operationalized, and they do not need multi-staged design processes. As Hudson et al. (2001) reveals, the PMS has to accommodate strategic changes while being resource effective. The SMEs are flat organisations and are usually manager-owned businesses; hence, these kinds of changes are easy to make. The FPM offers a new kind of 'mindset'. Managers can trust that they have the right measures in place to produce 
Pekkola, S., Saunila, M. \& Rantanen, H. (2016). Performance measurement system implementation in a turbulent operating environment. International Journal of Productivity and Performance Management, 65(7), 947-958.

information on profitability, but on the other hand they can easily create new ones to meet their current needs without fear that they will lose knowledge of the operation's profitability.

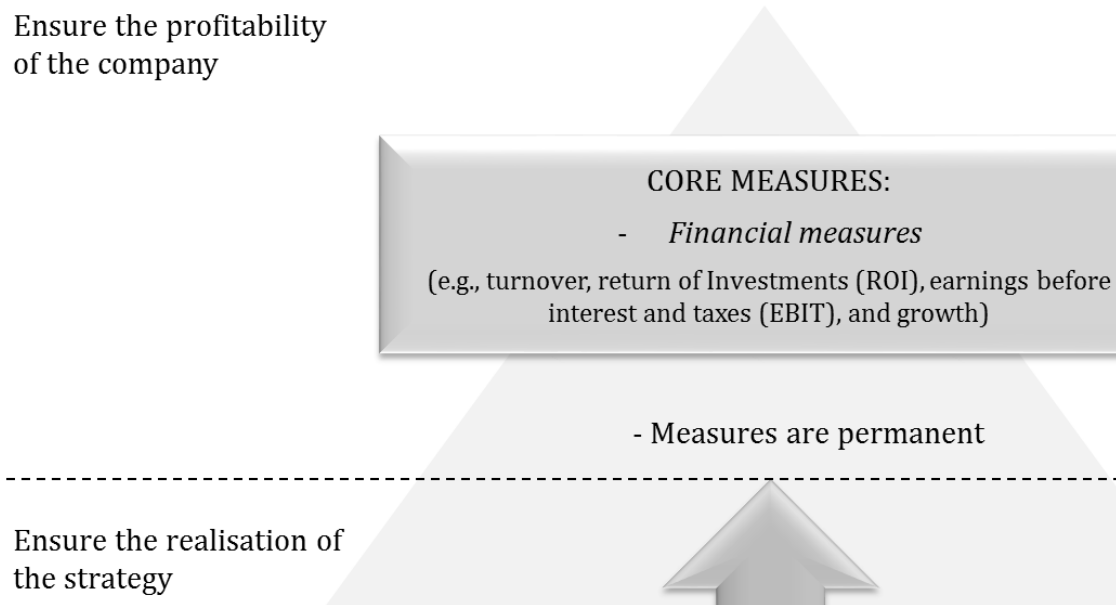

- Measures are permanent

Ensure the realisation of the strategy

Figure 1. Framework for a flexible PMS for SMEs

The FPM framework can be considered a response to the need, pointed out in the literature, for a structured methodology to design and implement a PMS for SMEs operating in a turbulent environment (Garengo, 2005; Cocca and Alberti, 2010; Bititci et al., 2012; Nudurupati et al., 2011). It replaces the resource-intensive and multi-stage frameworks and models and creates a starting point for operationalising some of the previously presented requirements related to a PMS for SMEs in turbulent operating environments. The lack of human resources and limited skills are further challenges to implementing PMSs in SMEs. This framework offers SMEs a useful tool for concentrating on a few essential measures to face the challenges of a turbulent environment. To summarise, the proposed FPM framework is dynamic and flexible and enables quick strategic changes. It is not too strategy oriented, and its starting point is to ensure the company's productivity and profitability. When using this framework, the selected measures have an explicit purpose and are relevant and simple to understand and use. 
Pekkola, S., Saunila, M. \& Rantanen, H. (2016). Performance measurement system implementation in a turbulent operating environment. International Journal of Productivity and Performance Management, 65(7), 947-958.

\section{CONCLUSIONS}

This study proposed a flexible performance measurement framework for SMEs in a turbulent operating environment. Earlier studies (see, e.g., Hudson et al., 2001; Cocca and Alberti, 2010; Bahri et al., 2011) concentrated on the development of performance measurement process models for SMEs, but most of these models do not take into account the challenges of a turbulent environment. Bititci et al. (2012) and Nudurupati et al. (2011) highlight the need to understand how a PMS could adapt in SMEs to a rapidly changing operating environment. The study combines the current literature from PMS in SMEs and empirical evidence from a longitudinal single case study.

Prior literature has identified the following characteristics for PMSs in SMEs: PMSs should have an owner focus, high flexibility, fast fit to market changes, less process formalisation and should focus on an SME's daily business. Based on these characteristics, this study has proposed a flexible performance measurement system (FPM) framework for SMEs. The FPM framework consists of two parts: core measures and supportive measures. The core measures are more permanent and illustrate the financial state of the company. The supportive measures can easily be changed and maintained to reflect the market and strategic changes. Because of the two measurement levels, the proposed framework is dynamic, flexible and enables quick strategic changes. It is not too strategy oriented, and its starting point is to ensure the company's productivity and profitability. The core measures always ensure the profitability of the company even though the supportive measures change often. The supportive measures can change as often as needed. These measures evaluate the current strategy choices and effectiveness of development actions.

The study has made the practical contribution of new knowledge about designing a performance measurement system for SMEs that can support the measurement-related development projects in the SMEs. The case descriptions can be regarded as illustrative examples for the design of a performance measurement system for SMEs. There are no perfect performance measurement systems, but there are many systems that satisfy the defined managerial needs reasonably well. In addition, cultural change and change management are needed to transform the 'mindset' towards performance development thinking.

The main limitation of this paper is that it has focused on only one case environment. Yet this is also a key strength; its longitudinal research approach made it possible to understand and develop performance measures in certain contexts. However, in the future, similar studies could be conducted in different contexts to identify the general principles in each context. Moreover, other longitudinal studies are needed to examine the effectiveness of these chosen approaches. Future research should also be carried out to arrive at an understanding of the wider applicability and 
Pekkola, S., Saunila, M. \& Rantanen, H. (2016). Performance measurement system implementation in a turbulent operating environment. International Journal of Productivity and Performance Management, 65(7), 947-958.

value of the framework. For example, general guidelines for applying the framework should be established.

\section{REFERENCES}

Ates, A., Garengo, P., Cocca, P. and Bititci, U. (2013), "The development of SME managerial practice for effective performance management", Journal of Small Business and Enterprise Development, Vol. 20 No. 1, pp. 28-54.

Bahri, M., St-Pierre, J. \& Sakka, O. (2011), "Economic value added: a useful tool for SME performance management", International Journal of Productivity and Performance Management, Vol. 60 Iss: 6, pp.603 - 621

Barrows, E. and Neely, A. (2011), Managing Performance in Turbulent Times: Analytics and Insight, John Wiley \& Sons, New Jersey.

Bititci, U.S., Carrie, A.S. and McDevitt, L. (1997), “Integrated performance measurement systems: a development guide", International Journal of Operations \& Production Management, Vol. 17 No. 5, pp. 522-34.

Bititci, U.S., Garengo, P., Dörfler, V. and Nudurupati, S. (2012), "Performance measurement: challenges for tomorrow", International Journal of Management Reviews, doi:10.1111/j.1468-2370.2011.00318.x

Brem, A., Kreusel, N. and Neusser, C. (2008), "Performance measurement in SMEs: literature review and results from a German case study", International Journal of Globalisation and Small Business, Vol.2, No.4, pp. 411 - 427

Cassell, C., Nadin, S. and Gray, O.M. (2001), "The use and effectiveness of benchmarking in SMEs”, International Journal of Benchmarking, Vol. 8 No. 3, pp. 212-22.

Chennel, A.F., Dransfield, S. Field, J. Fisher, N. Saunders, I. and Shaw, D. (2000), "OPM: a system for organisational performance measurement", Proceedings of the performance measurement - Past, Present and Future conference, Cambridge, 19-20 July.

Cocca, P. and Alberti, M. (2010), "A framework to assess performance measurement systems in SMEs”, International Journal of Productivity and Performance Management, Vol. 59 No. 2, pp. 186-200.

De Toni, A. and Tonchia, S. (2001), "Performance measurement systems - models, characteristics and measures", International Journal of Operations \& Production Management, Vol. 21 Iss: $1 / 2$, pp. $46-71$

Eisenhardt, K.M. (1989), "Building theories from case study research", The Academy of Management Review, Vol. 14 No. 4, pp. 532-50. 
Pekkola, S., Saunila, M. \& Rantanen, H. (2016). Performance measurement system implementation in a turbulent operating environment. International Journal of Productivity and Performance Management, 65(7), 947-958.

The Federation of Finnish Enterprises (2013), "Statistics of entrepreneurship", available at: http://www.yrittajat.fi/File/37743568-32d9-43d0-be64-6ebd7f02309e/enterprises2013.pdf (accessed 10 December 2014).

Garengo, P., Biazzo, S. and Bititci, U. (2005), "Performance measurement in SMEs: a review for a research agenda", Journal of Enterprise Information Management Reviews, Vol. 7 No. 1, pp. 25-47.

Gooderham, G. (2001), "The top 10 lessons of implementing performance management systems", Journal of Cost Management, Vol. 15 No. 1, pp. 29-33.

Hudson, M., Smart, A. and Bourne, M. (2001), "Theory and practice in SME performance measurement systems", International Journal of Operations \& Production Planning, Vol. 21 No. 8, pp. 1096-1115.

Hudson-Smith, M. and Smith, D. (2007), "Implementing strategically aligned performance measurement in small firms", International Journal of Production Economics, Vol.106, Iss: 2, pp. 393-408.

Kaplan, R.S. and Norton, D.P. (1996), The Balanced Scorecard: Translating Strategy into Action, Harvard Business School Press, Boston.

Kennerly, M. and Neely, A. (2003), "Measuring performance in a changing business environment", International Journal of Operations \& Production Management, Vol. 23 No. 2, pp. 213-29.

Laitinen, E.K. (1996), "Framework for small business performance measurement: towards integrated PM system", Research paper, University of Vaasa, Vaasa.

McAdam, R. (2000), "Quality models in an SME context: A critical perspective using a grounded approach”, International Journal of Quality \& Reliability Management, Vol. 17 Iss: 3, pp. 305 $-323$

Neely, A., Adams, C. and Kennerley, M. (2002), The Performance Prism: The Scorecard for Measuring and Managing Business Success, FT Prentice Hall, London.

Nudurupati, S.S., Bititci, U.S., Kumar, V. and Chan, F.T.D. (2011), "State of the art literature review on performance measurement", Computers \& Industrial Engineering, Vol. 60, pp. 279-90.

Rantanen, H. (2001), "Internal obstacles restraining productivity improvement in small Finnish industrial enterprises", International Journal of Production Economics, Vol. 69 No. 1, pp. 8591.

Rompho, N. (2011), "Why the balanced scorecard fails on SMEs: a case study", International Journal of Business and Management, Vol. 6 No. 11, pp. 39-46. 
Pekkola, S., Saunila, M. \& Rantanen, H. (2016). Performance measurement system implementation in a turbulent operating environment. International Journal of Productivity and Performance Management, 65(7), 947-958.

Simons, R. (2000), Performance Measurement and Control Systems for Implementing Strategy. Prentice Hall, Upper Saddle River, NJ.

Singh, R.K., Garg, S.K. and Deshmukh, S.G. (2008), "Strategy development by SMEs for competitiveness: a review”, Benchmarking: An International Journal, Vol. 13 No. 5, 525-47.

Sousa, S.D., Aspinwall, E.M. and Guimarães Rodrigues, A. (2006), "Performance measures in English small and medium enterprises: survey results", Benchmarking: An International Journal, Vol. 13 Nos. 1/2, pp. 120-34.

Taylor, A. and Taylor, M. (2014), "Factors influencing effective implementation of performance measurement systems in small and medium-sized enterprises and large firms: a perspective from contingency theory", International Journal of Production Research, Vol. 52 No. 3, pp. 847-66.

Tenhunen, J., Rantanen, H. and Ukko, J. (2001), 'SME-oriented Implementation of a performance measurement system", Proceedings of ISPIM 2001 - "Challenges of Innovation and Technology Management for the New Millennium", The 13th International Conference Lappeenranta, Finland, June 18th - 20th 2001.

Voss, C., Tsikriktsis, N. and Frohlich, M. (2002), "Case research in operations management", International Journal of Operations \& Production Management, Vol. 22, No. 2, pp. 195-219.

Yin, R.K. (2003), Case Study Research - Design and Methods, 4th ed., Sage Publications, Thousand Oaks, CA. 